\title{
Effect of Linguistic Differences and Formal Training on Scholarly Productivity
}

\author{
Don Baridam ${ }^{1 *} \quad$ Letam Don-Baridam Ngobe ${ }^{2}$ \\ 1.Faculty of Management Sciences, Akwa Ibom State University, Obio Akpa Campus, P.M.B. 1167, Uyo, Akwa \\ Ibom State, Nigeria \\ 2. Rivers State University, Port Harcourt, Nigeria
}

\begin{abstract}
The objective of this study was to find out the effect of linguistic differences and formal training on scholarly productivity among lecturers in Administrative Sciences. Data were obtained from 176 faculty members in Administrative Sciences drawn from 11 universities in Quebec Canada. Also, personal interviews were held with the deans and directors of research in seven of the eleven universities. The result of our findings showed statistically significant difference in total book production between those with working knowledge in both French and English. And those with working ability in only French or English. There was no significant difference in total article production between those with working ability in both French and English and those with working knowledge in only French or English. There was no significant relationship between the extent to which research is encouraged in the faculty in which the faculty members had their graduate training and scholarly productivity. Based on these findings, it was concluded that linguistic ability affects scholarly productivity. Also, commitment to scholarly activity cannot be enforced. It must come as a product of the enthusiasm that a faculty member feels toward his or her job. The implications for this study along with some directions for further study are addressed. Keywords: linguistic ability, formal training, scholarly productivity.
\end{abstract}

DOI: $10.7176 / \mathrm{EJBM} / 12-23-12$

Publication date:August $31^{\text {st }} 2020$

\section{Introduction}

There are several studies on the correlates of scholarly productivity (Rerstad and Aksnes, 2015, Sotudeh and Khoshian, 2013, Fox, 2000). However, while there are few studies on the relationship between linguistic differences, formal training and scholarly productivity, there is no significant study on the effect of linguistic ability and formal training on scholarly productivity among scholars in administrative sciences in Quebec Universities. It is for this reason that this study seeks to find out the effect of linguistic differences and formal training on scholarly productivity among scholars in Faculties of Administrative Sciences in Quebec universities.

\section{Review of Literature}

\subsection{Linguistic Differences.}

Productive researchers contribute information to their colleagues in a number of ways. These may include published articles, books, papers presented at conferences, informal contacts with others in the same specialty at different institutions and contacts with members of different disciplines. According to Hagstrom (1965), "highly involved leaders participate a great deal in all communication channels within specific discipline. They publish a great deal, receive formal recognition, participate in society activities, correspond, visit others and are visited by them, and spend more time in discussion with colleagues" (p.43). the ease with which they get involved in these activities depends in part, on their linguistic abilities. Similarly, Carrie et.al. (2020) Vokovic and Lesaux (2013) maintain that there is and academic performance. According to Lehitomen et.at; (2018) and Donnelly et.at.92019), bilingualism is associated enhanced executive functioning in adults.

Moch (1980, p.299) attributes differences in work behaviour to beliefs, values, or psychological states that predispose members of different cultures to respond differently to their experiences in the organization. The frame of reference the individual brings with him/her to the job is a determinant of the satisfaction he/she is likely to derive from it. It stands to reason, therefore, that the degree of an individual's involvement in publication activity depends to some extent upon the beliefs and values he holds about the outcome of such involvement. While these beliefs, values or psychological state may disappear to some extent as one gets fully assimilated in the new culture, the beliefs and values carried along from old culture cannot br eliminated in toto.

An individual's behaviour exhibited both on and off the job is a function of the saliency of need states within such person. At any given moment, "the saliency on the importance of different needs for the individual is determined by the individual's "past experiences with groups of which he or she was a member (socialization process) and with jobs that he or she has held" (Kanungo, 1979, p. 132). Different groups of people are influenced by different cultural, group, and organizational norms, and thus they tend to develop different need structures or to set different goals and objectives for their lives. For example, Kanungo, in his study $(1979$, p.132) demonstrated that because of differences in the socialization process, francophone and anglophone managers exhibit different 
patterns of need saliency at work. For instance, security and affiliation needs seem to have greater saliency for francophone managers whereas autonomy and achievement needs tend to have greater saliency for anglophone as compared to francophone managers. The salient needs tend to determine the central life interests of the individual. With respect to publication involvement, the saliency of need in a faculty member may be reinforced when he or she finds that through involvement in publication activity he or she is capable of meeting the needs.

In her study of social organization, Smircich (1983) posits that organised activity depends on shared meanings that are prevalent within a culture. Organised activity, she continues, depends on the existence of shared schemes or contexts of interpretation, which allows action to be aligned in a coherent way" (Smircich, 1983, p.27). If this line of reasoning is correct, one could expect some differences in the publication outputs among francophone and anglophone lecturers.

To what extent does this linguistic difference affect publication among lecturers in Quebec universities? According to Zur-Muehlen (1979), a major publication problem faced by management faculty is the lack of Canadian outlets for publication. Because they are frequently compelled to submit their work to foreign journals, notably American Journals, Canadian content is often minimised. This situation is particularly difficult for faculty members who have very little or no working knowledge of the English language. Since the primary reference group of the individual is composed of those who read his published work, it is right to say that those who cannot communicate in the language that is understood by this group will have a hard time getting their works published in another language. What this implies is that faculty members are compelled to direct their works to European markets where again they are confronted with very stiff competition because of the limited publication outlets and different research tradition.

One could therefore hypothesised that:

Hypothesis 1: Faculty members with working ability in both French and English will have more publication outputs than those with working ability in only French or English.

\subsection{Formal Training of Faculty Members.}

Numerous studies (Andries, et.al. 2013, Lawler II, 1985; Murphy, 1985) have suggested that education may cause people to have different expectations and preferences with respect to work. Commenting on the effect of an individual's formal training on productivity, Murphy (1985:108) posits that the nature and diversity of the school an individual attend can cause a difference in productivity of scholars. The quality of the institution where an individual is trained is a critical socializing environment, not only because it develops knowledge, skills and competence, but also because it cultivates norms, values and attitudes. The formal training of an individual, therefore, plays a significant role in his scholarly production.

A research by Pelz and Andrews (1966) shows that high production is a function of a value system in which the scientist is oriented toward his /her discipline rather than his / her immediate institutional affiliation. Since institution operates as the local in which orientations to the discipline are internalized, it seems reasonable to assume that faculty members trained in less productive institutions are more productive than those trained in less productive institutions. According th Gaston (1978:719), graduate students in the more productive institutions are exposed to a socialization process which enables them to get ahead in becoming successful scientists.

Parallel to above view, Crane (1965) indicated that a productive scientist is more likely to transmit the appropriate skills and values to his students. "Scientists trained at (less productive) universities were less likely to have studied with highly productive scientists who could provide them with adequate model." The work of Muhammad and Fard (2013) reveals that employees who are well trained will exhibit better performance than their colleagues who are not exposed to better training.

There is a general consensus in the literature that graduates of minor departments seldom move to departments of higher quality, but rather are concentrated at lower levels of the academic hierarchy (Clemente and Sturgis, 1974:289). This limited upward mobility inhibits the productivity of graduates of minor departments in at least two ways:

First, scientists who eventually become high producers generally have their first jobs at an institution where they can engage in research. Since more funds, facilities, and released time are available at major departments, scientist who take jobs at this level have a greater chance to be productive." Second, individuals located in minor departments and undergraduate institutions do not have equal access to channels of scientific communications as those in the major departments (Clemente and Sturgis, 1974:289). Way et. al (2019) found that "faculty at prestigious institutions produced more scientific papers, receive more citations and scholarly awards, and are typically trained at more prestigious institutions than faculty with less prestigious appointment."

Parallel to the preceding findings, McCormick and Bernick (1982) in their study of those who publish in American universities, conclude that graduates of reputational schools produce the overwhelming portion of the publication output. Such overwhelming publication output stems from at least two reasons. First, prestigious departments demonstrate active research programmes which enhance the department's prestige and, more importantly for the current doctoral students, it models appropriate publication behaviour. Second, prestigious 
departments also engage in sponsorship of their doctoral students through their formal and informal contacts with another prestigious department. Development of these contacts can have tremendous effect on initial job placement and a surprisingly strong indirect effect on subsequent productivity of former doctoral students (Miller et al. 1985:4). Based on this set of propositions, the following hypothesis is advanced:

Hypothesis 2: There will be a positive and significant relationship between scholarly productivity and the extent to which research is encouraged in the faculty in which the faculty members had their graduate training.

\section{Methods}

A total of 557 copies of questionnaires were sent to full time faculty members in Faculties of Administrative Sciences in eleven Universities in Quebec, Canada. Responses were received from 176 faculty members with the number of participants per faculty ranging from 3 to 41 . The response rate for participants 32 per cent, rate falling within the 18 to 57 range found in previous studies of universities (See Everett, 1980; McNeece, 1981; Taylor, et.al. 1984). Beside the questionnaires, the lead author of this paper held personal interviews in seven universities. In each university, one dean, one director of research and two faculty members were interviewed. This triangulation of methodology was necessary in order to provide firsthand qualitative information which is needed to interpret the statistical results derived from the questionnaire.

\subsection{Operational Measures of Variables}

3.1.1 Dependent variable: No single operationalization of scholarly productivity will satisfy everyone; invariably, matters of judgment and preference often intrude to compound the problem of measurement. However, the specific dependent variable to which attention is given in this study is the self-reported articles in refereed and non-refereed journals, books, chapters in books, and papers presented or published in refereed conferences during the last five years. ${ }^{1}$

To estimate the validity of the responses, fifty faculty members were randomly selected from our sample, and their self-reported number of publications were compared with counts from the journals indicated from the same five -year period. Forty eight out of the 50 (96 per cent) responses were accurately identified, suggesting that the data were adequate for our purpose.

The measure of scholarly productivity was derived from answers to the following questions: Please indicate the number of scholarly publications or presentations on which your name appears as the sole author in the last five years. Please indicate the number of publications in which your name appears as one of two or more authors in the last five years. Because of the difficulty of establishing singular responsibility for joint publication, no differentiation was made in establishing scholarly productivity.

For this study, it was assumed that factors influencing article and book publications are not identical. It was therefore decided to perform separate but parallel analyses of article and book publications. Total articles were operationalized as the summation of all single-and multiple authored articles, chapters in books and papers published or presented in refereed conferences. A chapter in a book was regarded as equivalent to an article. Total books included the summation of single and multiple authored books.

3.1.2 Independent variables. Linguistic ability and formal training are the independent variables.

Linguistic Ability: Linguistic ability was measure by the faculty members' response to the following questions: "In which language (s) do you have a working ability.? French, English, both, other (Please specify)."

Formal Training: The measure of formal training was measured by the faculty members' estimation of the extent to which research is encouraged in the faculty in which they had their graduate training. In measuring this, respondents were asked the following question: "The faculty in which I had my graduate training placed great emphasis on research." Responses ranged from not all representative of my opinion (sore zero point) to a great extent representative of my opinion (score four points).

\subsection{Analyses}

The data were grouped for the whole population. Two separate but parallel analyses were performed on the scholarly productivity variables. That is all the single authored and multi-authored publications (except single and multi-authored books) were combined to form one production measure. All technical papers were excluded from the analysis. These are publications which are not diffused externally. The second measure included all single and multi-authored books. 
Table 1 Multivariate Analyses of Global Publication Production Measures on Linguistic Differences and Formal Training Variables (N- 176)

\begin{tabular}{|l|c|c|c|c|}
\hline $\begin{array}{l}\text { Scientific Productivity } \\
\text { Measures }\end{array}$ & \multirow{2}{*}{$\begin{array}{c}\text { Total Single } \\
\text { Articles }\end{array}$} & $\begin{array}{c}\text { Total multiple } \\
\text { Articles }\end{array}$ & $\begin{array}{c}\text { Total } \\
\text { Articles }\end{array}$ & $\begin{array}{c}\text { Total } \\
\text { Books }\end{array}$ \\
\cline { 1 - 4 } & B- Weights & B- Weights & B- Weights & B- Weights \\
\hline Linguistic Ability & $2.24^{0}$ & 0.91 & 2.06 & 0.24 \\
\hline Formal Training & 0.36 & 1.32 & 1.67 & 0.05 \\
\hline Intercept & -4.04 & 1.33 & -5.37 & 1.17 \\
\hline $\mathrm{R}^{2}$ & $.34^{* * *}$ & $.41^{* * *}$ & $.48^{* * *}$ & $.29^{*}$ \\
\hline $\mathrm{F}$ & 1.84 & 2.52 & 3.25 & 1.49 \\
\hline
\end{tabular}

${ }^{0} \mathrm{p}<0.1, * \mathrm{p}<.05, * * \mathrm{p}<.01 * * * \mathrm{p}<.001 \mathrm{~d} . \mathrm{f}$ : degree of freedom $=125^{\mathrm{a}}=$ non standardized

Table 2 Multivariate Analyses of Single Publication Production Measures on Linguistic Differences and Formal Training Variables (N-176)

\begin{tabular}{|l|c|c|c|c|c|c|}
\hline $\begin{array}{l}\text { Scientific Productivity } \\
\text { Measures }\end{array}$ & $\begin{array}{c}\text { Articles in } \\
\text { ref. Jrn. }\end{array}$ & $\begin{array}{c}\text { Articles in } \\
\text { non ref.jrn. }\end{array}$ & Books & $\begin{array}{c}\text { Chap. in } \\
\text { Books }\end{array}$ & $\begin{array}{c}\text { Papers } \\
\text { pub. in } \\
\text { ref. conf. }\end{array}$ & $\begin{array}{c}\text { Paper presented } \\
\text { at ref. conf. }\end{array}$ \\
\cline { 2 - 7 } & $\begin{array}{c}\text { B- } \\
\text { Weights }\end{array}$ & B- Weights & $\begin{array}{c}\text { B- } \\
\text { Weights }\end{array}$ & $\begin{array}{c}\text { B- } \\
\text { Weights }\end{array}$ & B-weight & B-weight \\
\hline Linguistic Ability & 0.53 & $1.25^{*}$ & 0.09 & 0.07 & $0.45^{*}$ & 0.26 \\
\hline Formal Training & 0.30 & 0.47 & -0.03 & 0.02 & 0.10 & 0.27 \\
\hline Intercept & 1.79 & 0.59 & 0.50 & 0.29 & -1.26 & -4.38 \\
\hline $\mathrm{R}^{2}$ & $.32^{*}$ & 0.26 & 0.26 & 0,27 & 0.27 & 0.25 \\
\hline $\mathrm{F}$ & 1.25 & 0.50 & 0.80 & 0.98 & .085 & 0.45 \\
\hline
\end{tabular}

${ }^{0} \mathrm{p}<0.1, * \mathrm{p}<.05, * * \mathrm{p}<.01 * * * \mathrm{p}<.001 \mathrm{~d} . \mathrm{f}$ : degree of freedom $=125 \mathrm{a}=$ non standardized

Table 3 Multivariate Analyses of Multiple Authored Publication Production Measures on Linguistic Differences and Formal Training Variables (N- 176)

\begin{tabular}{|l|c|c|c|c|c|c|}
\hline $\begin{array}{l}\text { Scientific Productivity } \\
\text { Measures }\end{array}$ & $\begin{array}{c}\text { Articles in } \\
\text { ref. Jrn. }\end{array}$ & $\begin{array}{c}\text { Articles in } \\
\text { non ref.jn. }\end{array}$ & Books & $\begin{array}{c}\text { Chap.in } \\
\text { Books }\end{array}$ & $\begin{array}{c}\text { Papers } \\
\text { pub. in } \\
\text { ref. conf. }\end{array}$ & $\begin{array}{c}\text { Paper presented } \\
\text { at ref. conf. }\end{array}$ \\
\cline { 2 - 7 } & $\begin{array}{c}\text { B- } \\
\text { Weights }\end{array}$ & B- Weights & $\begin{array}{c}\text { B- } \\
\text { Weights }\end{array}$ & $\begin{array}{c}\text { B- } \\
\text { Weights }\end{array}$ & B-Weight & B-Weight \\
\hline Linguistic Ability & 0.09 & 0.04 & 0.16 & $0.16^{*}$ & 0.40 & 0.44 \\
\hline Formal Training & 0.39 & 0.01 & 0.09 & 0.00 & .0 .08 & 0.41 \\
\hline Intercept & 2.82 & 0.07 & 0.67 & 2.13 & -4.38 & -1.97 \\
\hline $\mathrm{R}^{2}$ & $0.41^{* *}$ & $0.32^{*}$ & $0.31^{*}$ & $0.36^{* *}$ & $.30^{*}$ & $.33^{*}$ \\
\hline $\mathrm{F}$ & 2.07 & 1.20 & 1.10 & 1.39 & 1.05 & 1.24 \\
\hline
\end{tabular}

${ }^{0} \mathrm{p}<0.1, * \mathrm{p}<.05, * * \mathrm{p}<.01 * * * \mathrm{p}<.001 \mathrm{~d} . \mathrm{f}:$ degree of freedom $=125 \mathrm{a}=$ non standardized

Hypotheses 1 and 2 were tested using multivariate regression analysis.

\section{Results and Discussion}

Hypothesis 1: The hypothesis that faculty members with working ability in both French and English will have more publication outputs than those with working ability in only French or English was tested with multivariate analysis of variance.

Our analysis revealed no significant difference in total article production between those with working ability in both French and English $(\bar{X}=14.07)$ and those who can work in only French $(\bar{X}=9.36)$ or English $(\bar{X}=19.75)$. A significant difference was however, found in total book production between those who have working ability in both French and English $(\bar{X}=1.01)$ and those with working ability in only French $(\bar{X}=0.45)$ or English $(\bar{X}=1.50)$. This was significant at $(\mathrm{F}=3.05), \mathrm{df}=2 / 102, \mathrm{p} \leq 0.05)$. This result is in line with the comments received from the faculty members in some of the faculties were interviews where interviews were conducted. The faculty members stated that they were encouraged to produce books in French since more than 80 percent of the books currently used are in English. As in the words of the director of research from of the universities:

“...perhaps I should also tell you that book publication is very important for professors in Quebec universities. Right now, more than 80 percent of the books we use are in English. Our students and even so of my colleagues don't like this at all. Because of this, we encourage our faculties to publish books in French. This means that an individual with little or no article publication to his credit but has published 
one or more books is given equal consideration as one with article publications."

A further analysis of the single -authored publication measures revealed some significant differences in the mean production of single - authored papers published in refereed conferences between those who can work in both French and English $(\bar{X}=1.58)$ and their colleagues who can work only in French $(\bar{X}=0.56)$ or English $(\bar{X}$ $=1.13)$. This was significantly different at $(\mathrm{F}=3.59, \mathrm{df}=2 / 102, \mathrm{p} \leq 0.05)$, Our multivariate analysis of variance also revealed a significant difference in the mean production of multiple- authored books between those who can work in both French and English $(X=77)$ and those with working ability in only French $(=0.33)$ or English $(\mathrm{X}=1.00)$. This was significant at $(\mathrm{F}=2.82, \mathrm{df}=2 / 102, \mathrm{p} \leq 0.01)$.

It appears from this finding that those who have working ability in both French and English produce more single-authored papers published in refereed conferences than their colleagues who can work only in French or English. However, in terms of overall scholarly productivity, faculty members who have working ability in only English appear to produce more than their colleagues with working ability in only French or both French and English. This result is surprising. One would have expected those with working ability in both French and English to outproduce their colleagues with unilingual ability. While it might be true as Zur-Muehlen (1979) asserts, that the major publication problem faced by Canadian faculties is the lack of Canadian outlets, it appears a bit difficult to confirm this assertion based on the result of our findings.

Hypothesis 2. Relationship between formal training of the faculty member and scholarly productivity. The hypothesis that a positive and significant relationship will exist between the formal training of the faculty member and his or her scholarly productivity was tested with the multivariate regression procedure (see Table 1).

The relationship between formal training and production of articles (total) was statistically nonsignificant (beta $=0.5$, n.s). No statistically significant relationship was found between total book production and formal training (beta $=1.67$. n.s.). A further analysis on single-authored publication production measures also showed no statistical relationship on any of the production measures and formal training in the presence of controls for the effects of other independent variables. The lack of significant relationship is still a bit surprising in the light of the prevailing belief among academics that an individual's publication production is a function of his or her formal training. While it might be right to say, in part, that research competencies are acquired through the doctoral socialization process, it is worth mentioning also that the production of publication goes beyond this socialization process. As earlier mentioned, commitment to scholarly activity cannot be enforced. Rather it must come as a product of the enthusiasm that a faculty member feels toward his job.

The publication contributions of faculty members are a product of the emphasis a faculty placed on research, teaching and consulting in the appointment and promotion decisions. A faculty that places more emphasis on teaching experience would probably recruit prospective faculty members or promote its faculty members on the basis of long years of teaching. This appears to be the case in most of the faculties studied. While the 'publish and perish' dictum pervades most quarters of the academic world, including the Faculties of Administrative Sciences, faculty members continue to be recruited into universities based largely on teaching needs even though the same institution publicly applaud more for their publication accomplishments than for their successful teaching.

A further related reason why formal training appears not to be related to publication production is Lodahl and Gordon call the "predictability among disciplines." Lodahl and Gordon (1972) posited that teaching and research activities exhibit greater structure and predictability among disciplines with better developed paradigms. To the extent that such agreement has consequences for the reward system (Zuckerman and Merton 1973). The lack of consensus over the questions of theory and method with research collaborators in administrative sciences makes publication production difficult.

Finally, individuals vary in their abilities to cope with certain environment pressures. Inability to cope with these pressures only serve to impede scholarly productivity.

\section{Conclusion}

The relationships reported in this study underscore the multiplicity of factors which influence scholarly productivity. Though the response rate was relatively small to draw accurate inferences about the population for Administrative Sciences Faculties, it provides some understanding of the relationship between linguistic ability and formal training of faculty members and scholarly productivity. The scope of this inquiry has permitted, at least in part, examination of the relationships between two independent variables - linguistic ability and formal training of the faculty member and their effects on scholarly productivity among scientists in Administrative Sciences in Quebec universities. From the findings in this study, it is reasonable to conclude that linguistic ability to some extent has significant influence on scholarly productivity, particularly for those with working knowledge of English.

The implications of this finding for practitioners are quite significant. It suggests that scholars with working knowledge of a second language are more likely to produce more publications than their colleagues with working knowledge in only one language.

The fact that there was no significant relationship between formal training and scholarly productivity presents 
serious implications for university decision makers. Universities that place more emphasis on teaching at the expense of research production will score low in their ranking. This is because research volume and research influence are among the performance indicators in the ranking of universities worldwide. The present study focused on scholars in administrative sciences. Future study should be conducted on scholars in a different society using similar hypotheses.

${ }^{\text {IS }}$ Scientific productivity of faculty members who have been in the university for less than five years were adjusted to account for the five-year period. This was adjusted as follows: Total number of publications $\mathrm{x} 5$ years/number of years in the academic profession.

\section{References}

Andries D.G and Sauermann, J. (2013) "Effect of Training on Productivity: The Transfer of ON -the -Job training from the Perspective of Economics research" Educational Research Review. Vol. 8 (January), pp. 28-36

Cameron, C. et.al. (2020) "The Role of Scientific Communication in Predicting Science Identity and Research Career Intention,” Plos pone (January) 19. https: ://doi.org/journal.pone.0228197

Clemente, F. and Sturgis, R. B. (1974), "Quality of Department of Doctoral training and Research Productivity." Sociology of Education, Vol. 47, No.2, (Spring), pp. 287-299

Crane, D. (1965), "Scientists at Major and Minor Universities: Some Factors Affecting the Selection of Articles for Scientific Journals." The American Sociologist, Vol. 30, (October), pp.699-714

Donnelly, S. et.al; (2019) Control Tasks? A Meta-analysis of Global Reaction time and Interference Cost," Psychonomic Bulletin and Review, 26 (4), pp. 1122-1147

Everett, J.E. (1980) "Work Related Attitudes of Academic Staff at Australian Universities and Colleges. Journal of Higher Education, Volume 2, pp.271-282.

Fox, M. F. (2005), 'Gender, Family characteristics and Publication Productivity among scientists' Social Studies of Science, 1(35), 5 - 33.

Gaston, J. (1978), The Reward System in British and American Sciences. New York, Wiley.

Hagstrom, W. O. (1965), The Scientific Community. New York, Basic Books Inc.

Kanungo, R. N. (1979, “The Concepts of Alienation and Involvement Revisited." Psychological Bulletin, Vol. 86, No.1. (October), pp. 119-138

Lawler Edward E. III (1985), "Education, Management Styles, and Organizational Effectiveness," Personnel Psychology, Vol.38, No.1, (Spring) pp.1-26

Lehitonen, M, et. al. (2018), "Is Bilingualism Associated with Enhanced Executive Functioning in Adults? A Meta -analytic review," Psychological Bulletin 144(4), pp. 394-425

McCormick, J. M. and Bernick, L.E. (1982), "Graduate Training and Productivity: A Look at Who Publishes." Journal of Politics, Vol.44, pp. 212-227.

McNeece, C.A. (1981) "Faculty Publications, tenure and Job Satisfaction in Graduate Social Work Programs." Journal of education for Social Work, Volume 17, pp.13-19

Miller, C. et. al. (1985), "Developing researchers in Organisation and Management Theory: Methods for Improving Program success." Department of Management CBA 4.202, University of Texas, Austin.

Moch, M. K. (1980), “Testing Four Common Explanations,” Journal of Applied Psychology, Vol. 65, No. 3, pp. 299-306

Muhammad, M. and Fard, R.Y. (2013), "The Impact of Employee Training and Development on Employee productivity," Global Journal of Commerce and Management Perspective, (November-December), Vol. 2, (6), pp. 91-93

Murphy, J. L (1985), “Does the Difference Schools Make, Make a difference?” The British Journal of Sociology, Vol.XXXVI, No. 1. (March), pp.106-116

Pelz, D. C. \& Andrews, F. M. (1966), Scientists in Organizations. New York: John Wiley and Sons Inc.

Smircich, L. (1983), "Studying Organisations as Cultures," In Gareth Morgan (ed. Beyond Method. Sage Publications. Pp. 160-172

Taylor, S. M. et. al. (1984), "Type A Behaviour and Faculty research Productivity: What Are the Mechanisms?" Organizational Behaviour and Human Performance, Volume 34, pp.402-418

Rorstad, K. \& Aksnes, D.W. (2015), "Publication Rate Expressed by Age, Gender and Academic Position-A Large Scale Analysis of Norwegian Academic Staff," Journal of Informetric vol. 9, issues 2, (April), 1-4 XII, No.9 (whole no. 462).

Sotudeh, H. and Khoshian, N. (2013), "Gender Differences in Science: The Case of Scientific Productivity in Nano Science \& Technology during 2005-2007," Sociometric. (May) 17

Vukovic R. and Lesaux, N.K. (2013) "The Relationship Between Linguistic Skills and arithmetic Knowledge," Elsevier: Learning and Individual Differences Vol. 23 (February), pp. 87-91

Way, F. S. et, al (2019) "Productivity, Prominence, and the Effects of Academic Environment" Proceedings of the National Academy of Science of the United States of America. May 28, 116(22) 
Zur-Muehlen, M. V. (1979), "Managing in the 1980s: The Crisis in Management Education and research." Paper Presented at the Management Conference held at Toronto, October 2-3.

\section{About the authors:}

Don Baridam is a Professor of Organizational Behaviour. He was a former Vice-Chancellor, University of Port Harcourt, and Chairman, Committee of Vice-Chancellors of Federal Universities of Nigeria and also one-time Chairman, Association of Vice-Chancellors of Nigerian Universities. Baridam holds a BSc in Management from University of Wisconsin, an MBA from Northwest Missouri State University, Maryville, United States of America, and a $\mathrm{PhD}$ in Management with specialization in Organizational Behaviour from Laval University, Quebec, Canada. He is a member of the British Institute of Management, Institute of Marketing, London, and a Fellow, Academy of Management, Nigeria.

Letam Don-Baridam Ngobe is a lecturer at the Faculty of Management Sciences, Rivers State University, Port Harcourt, Nigeria. She holds a Bachelor of Science in Human Resources Management, Kwame Nkrumah University of Science and Technology, Kumasi Ghana, an MSc in Human Resources Management from Brunel University, London and a Ph.D. in Human Resources Management from the University of Port Harcourt. 